\title{
Associations Between Practice-Related Changes in Motor Performance and Muscle Activity in Healthy Individuals: A Systematic Review
}

Dennis Brueckner ${ }^{1,2}$, Rainer Kiss ${ }^{3}$ and Thomas Muehlbauer ${ }^{2^{*}}$

\begin{abstract}
Background: A well-learned motor skill is characterized by the efficient activation of muscles that are involved in movement execution. However, it is unclear if practice-related changes in motor performance correlate with those in quantitative markers of muscle activity and if so, whether the association is different with respect to the investigated muscle (i.e., agonist and antagonist) and quantitative myoelectric parameter.

Thus, we conducted a systematic review and characterized associations between practice-related changes in motor performance and muscle activity in healthy individuals.

Methods: A computerized systematic literature search was performed in the electronic databases PubMed, Web of Science, and SPORTDiscus up to September 2017 to capture all relevant articles.

A systematic approach was applied to evaluate the 1670 articles identified for initial review. Studies were included only if they investigated healthy subjects aged 6 years and older and tested at least one measure of motor performance (e.g., error score, movement time) and quantitative muscle activity (i.e., amplitude domain: iEMG [integrated electromyography], RMS [root mean square]; time domain: duration of muscle activity, time to peak muscle activation). In total, 24 studies met the inclusionary criteria for review.

The included studies were coded for the following criteria: age, learning task, practice modality, and investigated muscles (i.e., agonist and antagonist). Correlation coefficients for the relationship of motor performance changes with changes in electromyography (EMG) amplitude, and duration were extracted, transformed (i.e., Fisher's $z$-transformed $r_{z}$ value), aggregated (i.e., weighted mean $r_{z}$ value), and back-transformed to $r$ values. To increase sample size, we additionally extracted pre and post practice data for motor performance and myoelectric variables and calculated percent change values as well as associations between both. Correlations were classified according to their magnitude (i.e., small $r \leq 0.69$, medium $r \leq 0.89$, large $r \geq 0.90$ ).

Results: Five studies reported correlation coefficients for the association between practice-related alterations in motor performance and EMG activity. We found small associations (range $r=0.015-0.50)$ of practice-related changes in motor performance with measures of agonist and antagonist EMG amplitude and duration. A secondary analysis (17 studies) that was based on the calculation of percent change values also revealed small correlations for changes in motor performance with agonist ( $r=-0.25,11$ studies) and antagonist ( $r=-0.24,7$ studies) EMG amplitude as well as agonist ( $r=0.46,8$ studies) and antagonist $(r=0.29,5$ studies) EMG duration.

(Continued on next page)
\end{abstract}

\footnotetext{
* Correspondence: thomas.muehlbauer@uni-due.de

${ }^{2}$ Division of Movement and Training Sciences/Biomechanics of Sport,

University of Duisburg-Essen, Gladbecker Str. 182, 45141 Essen, Germany

Full list of author information is available at the end of the article
} 
(Continued from previous page)

Conclusions: Our systematic review showed small-sized correlations between practice-related changes in motor performance and agonist and antagonist EMG amplitude and duration in healthy individuals. These findings indicate that practice-related changes can only partly be explained by quantitative myoelectric measures. Thus, future studies investigating biomechanical mechanisms of practice-related changes in motor performance should additionally include qualitative measures of muscle activity (e.g., timing of muscle activity, level of coactivation) and other biomechanical variables (i.e., kinetics, kinematics).

Keywords: Motor learning, Skill acquisition, Muscle activation, Electromyography (EMG), Muscles, Agonist, Antagonist, EMG amplitude and duration, Human

\section{Key Points}

- The present systematic review characterized associations between practice-related changes in motor performance and muscle activity in healthy individuals.

- Irrespective of the investigated myoelectric parameter (i.e., amplitude and duration) and muscle (i.e., agonist and antagonist), our analyses revealed small-sized correlations between changes in motor performance and muscle activity following motor practice.

- The observed small associations imply that practicerelated changes in motor performance can only partly be explained by quantitative myoelectric measures, and thus, we recommend to additionally include qualitative measures of muscle activity (e.g., timing of muscle activity, level of coactivation) and other biomechanical variables (i.e., kinetics, kinematics) in future investigations.

\section{Background}

Motor learning is defined as the changes, associated with practice or experience, in internal processes that determine a person's capability for producing a motor skill [1]. For example, as learning a motor skill progresses, movement error and duration are reduced. These performance improvements are related to changes in the gradation and timing of force produced by the muscles involved in the skilled performance. The level and duration of muscle involvement during execution of a learned movement task is reflected in their myoelectric activity that can be recorded and displayed by the use of electromyography (EMG).

The effects of motor practice on myoelectric activity have been investigated for more than six decades. One of the first studies [2], conducted in the late 1950s, investigated relatively simple movements, i.e., participants practiced filing and chiseling for 2 to 6 weeks. For both tasks, practice resulted in an increased movement fluidity and a change in the EMG pattern from agonistantagonist coactivation early in practice to reciprocal activation of both muscles late in practice. Ten years later, Kamon and Gormley [3] confirmed this result using a more complex movement task. In their experiment, subjects practiced the single knee circle mount on the horizontal bar. Over the 3-month practice period, they found a fluent execution of the exercise that was accompanied by a shift from continuous and overlapped muscle activity to phasic muscle activation. Thus, reciprocal, phasic, or sequential muscle activation seems to be qualitative indicators of resulting changes in the muscle activation pattern due to motor practice.

Further research tried to extend these findings with the aim to establish quantitative parameters of practicerelated myoelectric changes. While some authors reported decreases $[4,5]$ in muscle activity following practice, others found increases $[6,7]$ or no changes $[8,9]$. Therefore, the current evidence is conflicting, with a lack of studies systematically reviewing practice-related myoelectric changes associated with those in motor performance in healthy subjects. Moreover, previous studies primarily examined the effects of practice on measures of motor performance and muscle activity, separately, but did not report the relationship between the two.

Consequently, there is still a gap in our knowledge regarding potential associations between practice-induced adaptations in motor performance and muscle activity. Further, if there is such an association, information on the direction (i.e., positive or negative) and size (i.e., small, medium, or large) of the correlations need to be examined. A review of this topic will provide a better understanding of motor control processes and is suitable to provide information on how these processes change with skill acquisition. From a more practical point of view, the presented line of research is needed to determine the influence of motor practice on myoelectric activity in order to get insights that can be used for the design and evaluation of practice programs. Thus, the aim of this systematic literature review was to characterize associations between practice-related changes in motor performance and muscle activity in healthy individuals considering different well-established EMG variables (i.e., amplitude domain: integrated EMG [iEMG], 
root mean square [RMS]; time domain: duration of muscle activity, time to peak muscle activation). Since motor learning is characterized by a reduction in the force level and the time required to execute the practiced task, EMG amplitude and duration should also decrease, especially for the agonist muscle.

\section{Methods}

\section{Literature Search}

A computerized systematic literature search was conducted in PubMed, Web of Science, and SPORTDiscus from January 1950 up to September 2017. The following Boolean search strategy was applied using the operators AND, OR, NOT: (((motor learning OR motor practice OR skill acquisition) AND (muscle activity OR muscle activation OR EMG analysis OR electromyographic activity OR neuromuscular activity) NOT (patients OR disease))). The search was limited to full-text original articles, human species, and English language. Further, we checked the reference lists of each included article in an effort to identify additional suitable studies for inclusion in the database.

\section{Selection Criteria}

To be eligible for inclusion, studies had to meet the following criteria: (a) participants of the experimental groups had to be healthy subjects and (b) at least one measure of motor performance and muscle activity had to be assessed in the study. Studies were excluded if (a) they investigated children (6-12 years), adolescents (1318 years), seniors ( $\geq 65$ years), patients, or people with diseases; (b) it was not possible to extract pre and post practice values from the results section; or (c) authors did not reply to our inquiries sent by email. Based on the predefined inclusion and exclusion criteria, two independent reviewers (DB, TM) screened potentially relevant papers by analyzing the titles, abstracts, and full texts of the respective articles to elucidate their eligibility. If no consensus was achieved between the two reviewers, a third reviewer (RK) was contacted.

\section{Coding of Studies}

Each study was coded for the following variables: number of participants, age, learning task, practice modality, investigated muscle, motor performance, and muscle activity outcomes. For the latter one, we divided in measures of EMG amplitude (e.g., iEMG, RMS) and duration (e.g., duration of muscle activity, time to peak activation). For studies that reported multiple parameters within these outcome categories, the most representative parameter was included for further analysis. With regard to EMG amplitude, iEMG was defined as the most important variable. In terms of EMG duration, duration of muscle activity was used. As a function of the respective motor performance measure (i.e., error score or number of successful hits), the pre to post practice change can be negative or positive. Thus, a negative percent change value would indicate practice-related performance improvements (i.e., decrease in error score), and a positive percent change value would indicate a performance decrement (i.e., increase in error score) following practice.

Statistical Analyses In a first approach, associations between practice-related changes in motor performance and muscle activity were assessed using the reported Pearson product-moment correlation coefficient $(r$ value). To pool $r$ values derived from different studies, "Fisher's $z^{\prime}$ transformation" was used, i.e., Pearson product-moment correlation coefficients were converted to the normally distributed variable $z^{\prime}$ (i.e., $z$ transformed $r_{z}$ value). The formula for the transformation is (Eq. 1):

$$
z^{\prime}=0.5[\ln (1+r)-\ln (1-r)]
$$

where $\ln$ is the natural logarithm [10]. In addition, the included studies were weighted according to the magnitude of the respective standard error $(S E)$. The formula for the calculation of the $S E$ is (Eq. 2):

$$
S E=1 / \sqrt{ }(N-3)
$$

where $N$ stands for the respective sample size [10]. Afterwards, weighted mean $r_{z}$ values were computed. To classify and interpret the correlation sizes, $r_{z}$ values were back-transformed to $r$ values. Based on the recommendations of Vincent [11], values of $0 \leq r \leq 0.69$ indicate small, $0.70 \leq r \leq 0.89$ medium, and $r \geq 0.90$ large sizes of correlation. In a second approach, pre and post practice data for motor performance and myoelectric variables were extracted from other studies to calculate percent change values. Afterwards, associations between practice-related changes in motor performance and muscle activity were computed.

\section{Results \\ Study Characteristics}

Figure 1 displays a flow chart that illustrates the different stages of the systematic literature search and the selection of articles over the course of the search. The initial search identified 1670 studies that were potentially eligible for inclusion. After removal of duplicates and exclusion of ineligible articles, 21 studies remained. We identified another three articles from the reference lists of the included articles. Therefore, 24 studies were included in the final analysis with 17 and 11 studies that investigated parameters of EMG amplitude and duration, respectively.

Table 1 illustrates the main characteristics of the included studies $(n=17)$ examining practice-induced 
adaptations on motor performance and measures of EMG amplitude. Fourteen studies ( $n=232$ subjects) were performed with young adults only [4-9, 12-19], one study $(n=12)$ with young and middle-aged adults [20], one study $(n=28)$ with young and old adults [21], and one study ( $n=22$ subjects) did not report subjects' age [22]. Maximal effort tasks (i.e., fast/ballistic accurate movements) were investigated in five studies $[6,16,19$, $20,22]$ and submaximal effort tasks (i.e., target oriented or time/velocity constrained) were examined in 12 studies $[4,5,7-9,12-15,17,18,21]$. The literature search revealed a number of practice sessions ranging from one to ten. The number of trials per session ranged from ten to 200 . One study reported a duration of $16 \mathrm{~min}$ per session [5]. The number of investigated agonist and antagonist muscles ranged from one to two.

Table 2 shows the main characteristics of the included studies $(n=11)$ that examined practice-related changes on motor performance and measures of EMG duration. Nine studies ( $n=159$ subjects) were conducted in young adults only $[6,9,13,16,23-27]$, one study $(n=12)$ with young and middle-aged adults [20], and one study $(n=28)$ with young and old adults [21]. Due to the possible influence of biological aging, data for the old adults were excluded from our data analyses. Maximal and submaximal effort tasks were used in four [6, 16, 20, 23] and seven studies [9, 13, 21, 24-27], respectively. One to ten practice sessions were performed that included ten to 120 trials per session. The number of studied agonist and antagonist muscles ranged from one to two.

\section{Associations Between Practice-related Changes in Motor Performance and Muscle Activity}

Five studies $[8,19-22]$ reported correlation coefficients for the association between practice-related changes in motor performance and myoelectric activity. Figure $2 \mathrm{a}, \mathrm{b}$ illustrates the relationships of motor performance with agonist and antagonist EMG amplitude, respectively. Weighted mean $r_{\mathrm{z}}$ values amounted to 0.55 for measures of agonist EMG amplitude $\left(I^{2}=40 \%\right.$, chi-square $=6.63$, $d f=4, p=0.16$, five studies: $[8,19-22])$ and 0.33 for outcomes of antagonist EMG amplitude $\left(I^{2}=0 \%\right.$, chisquare $=0.64, d f=3, p=0.002$, four studies: $[8,19,21$, $22])$. Back-transformed $r$ values of $0.50\left(R^{2}=25 \%\right)$ and $0.32\left(R^{2}=10 \%\right)$ indicated small correlations. Additionally, one study [21] reported a small correlation of motor performance with measures of agonist $\left(r_{\mathrm{z}}=0.36, r=0.347\right.$, $\left.R^{2}=12 \%\right)$ and antagonist $\left(r_{\mathrm{z}}=0.02, r=0.015, R^{2}=0 \%\right)$ EMG duration.

In addition, pre and post practice data for motor performance and myoelectric activity were extracted from 17 studies to calculate percent change values and associations between both. Figure 3 displays scatterplots for changes in motor performance with agonist (Fig. 3a) and antagonist EMG amplitude (Fig. 3b). Our analysis revealed negative, small associations of motor performance with agonist ( $r=-0.25, R^{2}=6 \%, p=0.283,11$ studies, 20 data points; Fig. 3a) and antagonist $\left(r=-0.24, R^{2}=6 \%\right.$, $p=0.043,7$ studies, 10 data points; Fig. 3b) EMG amplitude (Additional file 1: Table S1). Figure 4 shows scatterplots for alterations in motor performance with

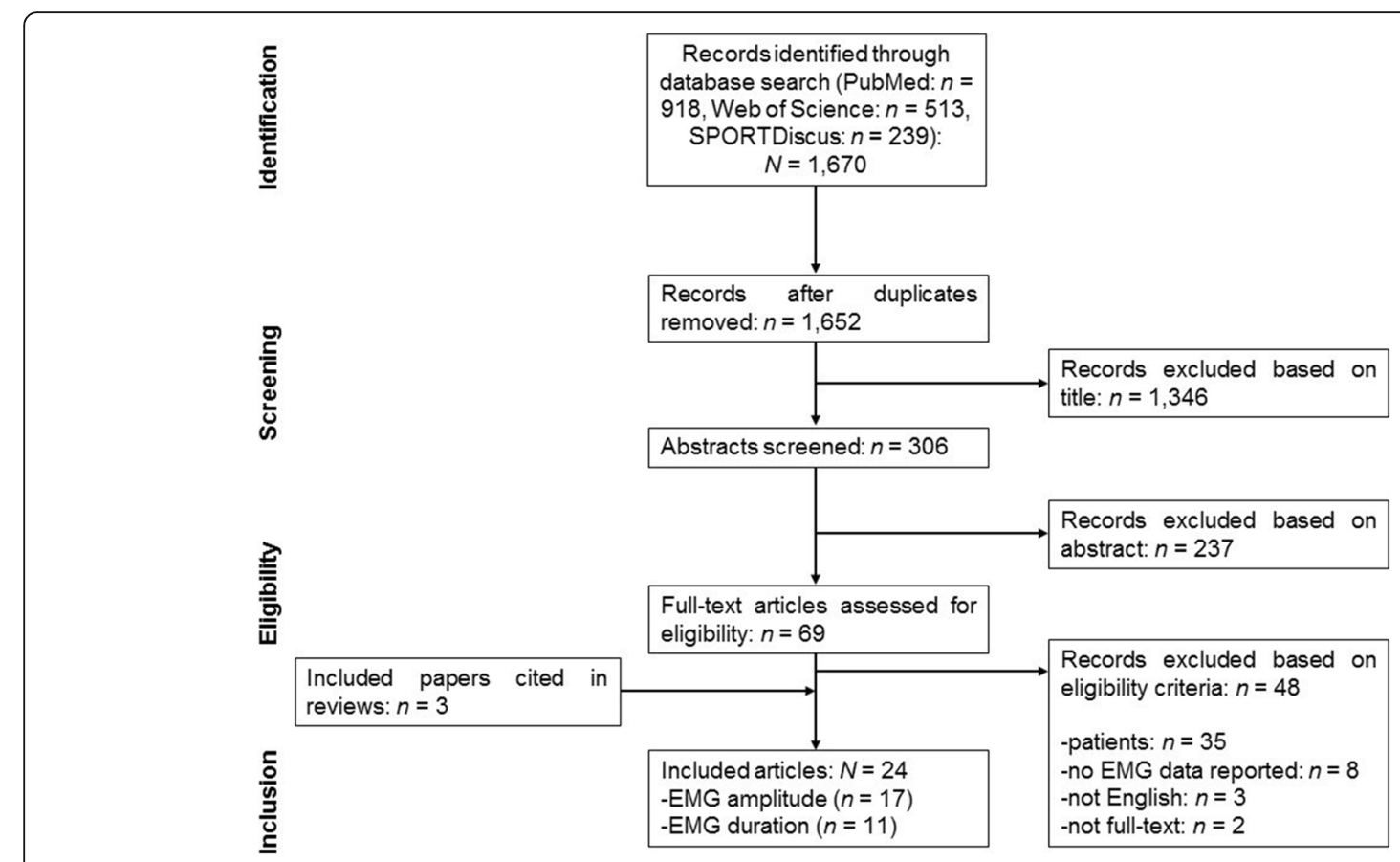

Fig. 1 Flow chart describing the systematic literature search. EMG electromyography 
Table 1 Studies ( $n=17$ ) examining learning effects on motor performance and measures of EMG amplitude

\begin{tabular}{|c|c|c|c|}
\hline Study & $\begin{array}{l}\text { Number of subjects; age } \\
\text { (range or mean } \pm \text { SD) }\end{array}$ & Learning task; practice modality & Investigated muscles \\
\hline Hobart et al. [12] & $31 ; 20-30$ years & $\begin{array}{l}\text { Submaximal effort task: target-oriented } \\
\text { underhand ball toss; } 1 \text { session; } 150 \\
\text { trials/session }\end{array}$ & $\begin{array}{l}\text { Agonist muscles: pectoralis major, } \\
\text { anterior deltoideus; } \\
\text { Antagonist muscles: posterior deltoideus, } \\
\text { triceps brachii }\end{array}$ \\
\hline Payton et al. [14] & $27 ; 20-34$ years & $\begin{array}{l}\text { Submaximal effort task: target-oriented } \\
\text { propelling of a plastic disc; } 1 \text { session, } 100 \\
\text { trials/session }\end{array}$ & Agonist muscle: abductor digiti quinti \\
\hline Hobart et al. [13] & $20 ; 20-30$ years & $\begin{array}{l}\text { Submaximal effort task: target-oriented } \\
\text { underhand ball toss; } 1 \text { session; } 104 \\
\text { trials/session }\end{array}$ & $\begin{array}{l}\text { Agonist muscle anterior deltoideus; } \\
\text { Antagonist muscle: posterior deltoideus }\end{array}$ \\
\hline Moore and Marteniuk [4] & 8; college-aged & $\begin{array}{l}\text { Submaximal effort task: time-constrained } \\
\text { (200 ms or } 500 \mathrm{~ms}) 45^{\circ} \text { horizontal forearm } \\
\text { extension; } 4 \text { sessions, } 100 \text { trials/session }\end{array}$ & $\begin{array}{l}\text { Agonist muscle: triceps brachii; } \\
\text { Antagonist muscle: biceps brachii }\end{array}$ \\
\hline Darling and Cooke [22] & $22 ; N R$ & $\begin{array}{l}\text { Maximal effort task: target-oriented elbow } \\
\text { flexion and extension (step tracking) with } \\
\text { increased movement velocity; } 1 \text { session, } \\
120 \text { trials/session }\end{array}$ & $\begin{array}{l}\text { Agonist and antagonist muscle: biceps } \\
\text { brachii, triceps brachii }\end{array}$ \\
\hline Engelhorn [9] & $16 ; 21$ years & $\begin{array}{l}\text { Submaximal effort task: time-constrained } \\
\text { horizontal elbow flexion; } 2 \text { sessions, } 120 \\
\text { trials/session }\end{array}$ & $\begin{array}{l}\text { Agonist muscle: biceps brachii; } \\
\text { Antagonist muscle: triceps brachii }\end{array}$ \\
\hline Dugas and Marteniuk [15] & 16; college-aged & $\begin{array}{l}\text { Submaximal effort task: target-oriented } 70^{\circ} \\
\text { and time-constrained ( } 900 \mathrm{~ms}) \text { forearm } \\
\text { extension; } 2 \text { sessions, } 100 \text { trials/session }\end{array}$ & $\begin{array}{l}\text { Agonist muscle: triceps brachii; Antagonist } \\
\text { muscle: biceps brachii }\end{array}$ \\
\hline Corcos et al. [19] & $5 ; 20-25$ years & $\begin{array}{l}\text { Maximal effort task: rapid elbow flexion; } 7 \\
\text { sessions, } 200 \text { trials/session }\end{array}$ & $\begin{array}{l}\text { Agonist muscle: biceps brachii; } \\
\text { Antagonist muscle: triceps brachii }\end{array}$ \\
\hline Heise [7] & $18 ; 22 \pm 2$ years & $\begin{array}{l}\text { Submaximal effort task: target-oriented } \\
\text { multi-joint throw; } 1 \text { session, } 55 \text { trials/session }\end{array}$ & $\begin{array}{l}\text { Agonist muscles: triceps brachii, posterior } \\
\text { deltoideus }\end{array}$ \\
\hline Gabriel and Boucher [6] & $18 ; 26 \pm 3$ years & $\begin{array}{l}\text { Maximal effort task: target-orientated rapid } \\
\left(\text { as fast as possible) elbow flexion }\left(0^{\circ} \text { to }\right.\right. \\
\left.75^{\circ}-90^{\circ}\right) ; 4 \text { sessions, } 100 \text { trials } / \text { session }\end{array}$ & $\begin{array}{l}\text { Agonist muscle: biceps brachii; } \\
\text { Antagonist muscle: triceps brachii }\end{array}$ \\
\hline Aggelousis et al. [8] & $41 ; 19-26$ years & $\begin{array}{l}\text { Submaximal effort task: target-oriented ball } \\
\text { throw by performing an elbow flexion; } 1 \\
\text { session, } 90 \text { trials/session }\end{array}$ & $\begin{array}{l}\text { Agonist muscles: biceps brachii, brachioradialis; } \\
\text { Antagonist muscles: triceps brachii, anconeus }\end{array}$ \\
\hline Gabriel [16] & $8 ; 25-30$ years & $\begin{array}{l}\text { Maximal effort task: target-orientated rapid } \\
\text { (as fast as possible) elbow flexion; } 4 \text { sessions, } \\
100 \text { trials/session }\end{array}$ & $\begin{array}{l}\text { Agonist muscle: biceps brachii; } \\
\text { Antagonist muscle: triceps brachii }\end{array}$ \\
\hline Lay et al. [5] & $6 ; 18-21$ years & $\begin{array}{l}\text { Submaximal effort task: ergometer rowing at } \\
\text { a fixed power output ( } 100 \mathrm{~W}) ; 10 \text { sessions, } \\
16 \mathrm{~min} / \mathrm{session}\end{array}$ & Agonist muscles: vastus lateralis, biceps brachii \\
\hline Christou et al. [21] & $\begin{array}{l}14 ; 24 \pm 2 \text { years } \\
14 ; 72 \pm 4 \text { years (excluded } \\
\text { from data analysis) }\end{array}$ & $\begin{array}{l}\text { Submaximal effort task: target-oriented } \\
\text { isometric contractions (abduction of the } \\
\text { index finger); } 1 \text { session including } 5 \text { blocks, } \\
20 \text { trials/block }\end{array}$ & $\begin{array}{l}\text { Agonist muscle: interosseus dorsalis l; } \\
\text { Antagonist muscle: interosseus palmares II }\end{array}$ \\
\hline Klein Breteler et al. [17] & 9; 29 years & $\begin{array}{l}\text { Submaximal effort task: manual spelling of } \\
\text { words; } 1 \text { session including } 7 \text { blocks, } 42 \\
\text { trials/block }\end{array}$ & $\begin{array}{l}\text { Agonist and antagonist muscles: dorsal } \\
\text { interosseus, abductor pollicis brevis, flexor } \\
\text { pollicis brevis, abductor digiti minimi, flexor } \\
\text { digitorum superficialis }\end{array}$ \\
\hline Hasson et al. [18] & $9 ; 25 \pm 4$ year & $\begin{array}{l}\text { Submaximal effort task: target-oriented force } \\
\text { production while maintaining a constant } \\
\text { pedaling speed; } 1 \text { session, } 18 \text { trials/session }\end{array}$ & $\begin{array}{l}\text { Agonist and antagonist muscles: tibialis anterior, } \\
\text { soleus, vastus lateralis, medial gastrocnemius, } \\
\text { rectus femoris, semitendinosus }\end{array}$ \\
\hline Liang et al. [20] & $12 ; 22-50$ years & $\begin{array}{l}\text { Maximal effort task: ballistic (maintain } \\
\text { maximum velocity) wrist flexion; } 10 \text { sessions, } \\
10 \text { trials/session }\end{array}$ & $\begin{array}{l}\text { Agonist muscle: flexor carpi radialis; } \\
\text { Antagonist muscle: extensor carpi radialis }\end{array}$ \\
\hline
\end{tabular}


Table 2 Studies ( $n=11$ ) examining learning effects on motor performance and measures of EMG duration

\begin{tabular}{|c|c|c|c|}
\hline Study & $\begin{array}{l}\text { Number of subjects; age } \\
\text { (range or mean } \pm \text { SD) }\end{array}$ & Learning task; practice modality & Investigated muscles \\
\hline Hobart et al. [13] & $20 ; 20-30$ years & $\begin{array}{l}\text { Submaximal effort task: target-oriented } \\
\text { underhand ball toss; } 1 \text { session; } 104 \text { trials/ } \\
\text { session }\end{array}$ & $\begin{array}{l}\text { Agonist muscle: anterior deltoideus; } \\
\text { Antagonist muscle: posterior deltoideus }\end{array}$ \\
\hline Ludwig [27] & $12 ; 18-22$ years & $\begin{array}{l}\text { Submaximal effort task: target-oriented } \\
\text { elbow extension; } 1 \text { sessions, } 100 \text { trials/ } \\
\text { session }\end{array}$ & $\begin{array}{l}\text { Agonist muscle: triceps brachii; } \\
\text { Antagonist muscles: biceps brachii }\end{array}$ \\
\hline Normand et al. [23] & 40; $19-35$ years & $\begin{array}{l}\text { Maximal effort task: target-oriented } \\
\text { (maximum speed) horizontal arm adduction } \\
\text { followed by a forearm flexion; } 8 \text { sessions, } 100 \\
\text { trials/session }\end{array}$ & $\begin{array}{l}\text { Agonist muscles: pectoralis major, biceps } \\
\text { brachii } \\
\text { Antagonist muscles: posterior deltoideus, } \\
\text { triceps brachii }\end{array}$ \\
\hline McGrain [24] & 16; college-aged & $\begin{array}{l}\text { Submaximal effort task: velocity-constrained } \\
\text { ( } 5 \text { mph) knee extension; } 1 \text { session, } 20 \text { trials/ } \\
\text { session }\end{array}$ & $\begin{array}{l}\text { Agonist muscles: vastus lateralis, vastus } \\
\text { medialis }\end{array}$ \\
\hline Engelhorn [9] & $16 ; 21$ years & $\begin{array}{l}\text { Submaximal effort task: target-oriented } \\
\text { horizontal elbow flexion; } 2 \text { sessions, } 120 \text { trials/ } \\
\text { session }\end{array}$ & $\begin{array}{l}\text { Agonist muscle: biceps brachii; } \\
\text { Antagonist muscle: triceps brachii }\end{array}$ \\
\hline Gabriel and Boucher [25] & $17 ; 19-32$ years & $\begin{array}{l}\text { Submaximal effort task: target-orientated } \\
\text { elbow flexion }\left(0^{\circ} \text { to } 75^{\circ}-90^{\circ}\right) ; 4 \text { sessions, } 100 \\
\text { trials/session }\end{array}$ & Antagonist muscle: triceps brachii \\
\hline Morrison and Anson [26] & $12 ; 18-25$ years & $\begin{array}{l}\text { Submaximal effort task: target-orientated dart } \\
\text { throwing task; } 2 \text { sessions, } 80 \text { trials/session }\end{array}$ & $\begin{array}{l}\text { Agonist muscle: triceps brachii; } \\
\text { Antagonist muscles: brachioradialis, biceps } \\
\text { brachii }\end{array}$ \\
\hline Gabriel and Boucher [6] & $18 ; 26 \pm 3$ years & $\begin{array}{l}\text { Maximal effort task: target-orientated rapid } \\
\left(\text { as fast as possible) elbow flexion }\left(0^{\circ} \text { to }\right.\right. \\
\left.75^{\circ}-90^{\circ}\right) ; 4 \text { sessions, } 100 \text { trials/session }\end{array}$ & $\begin{array}{l}\text { Agonist muscle: biceps brachii; } \\
\text { Antagonist muscle: triceps brachii }\end{array}$ \\
\hline Gabriel [16] & $8 ; 25-30$ years & $\begin{array}{l}\text { Maximal effort task: target-orientated rapid } \\
\text { (as fast as possible) elbow flexion; } 4 \text { sessions, } \\
100 \text { trials/session }\end{array}$ & $\begin{array}{l}\text { Agonist muscle: biceps brachii; } \\
\text { Antagonist muscle: triceps brachii }\end{array}$ \\
\hline Christou et al. [21] & $\begin{array}{l}14 ; 24 \pm 2 \text { years } \\
14 ; 72 \pm 4 \text { years (excluded from } \\
\text { data analysis) }\end{array}$ & $\begin{array}{l}\text { Submaximal effort task: target-oriented } \\
\text { isometric contractions (abduction of the } \\
\text { index finger); } 1 \text { session including } 5 \text { blocks, } \\
20 \text { trials/block }\end{array}$ & $\begin{array}{l}\text { Agonist muscle: interosseus dorsalis l; } \\
\text { Antagonist muscle: interosseus palmares ॥ }\end{array}$ \\
\hline Liang et al. [20] & $12 ; 22-50$ years & $\begin{array}{l}\text { Maximal effort task: ballistic (maintain } \\
\text { maximum velocity) wrist flexion; } 10 \\
\text { sessions, } 10 \text { trials/session }\end{array}$ & $\begin{array}{l}\text { Agonist muscle: flexor carpi radialis; } \\
\text { Antagonist muscle: extensor carpi radialis }\end{array}$ \\
\hline
\end{tabular}

EMG duration for agonist (Fig. 4a) and antagonist muscles (Fig. 4b). Our analysis yielded positive, small associations of motor performance with agonist $(r=$ $0.46, R^{2}=21 \%, p=0.095,8$ studies, 14 data points; Fig. 4a) and antagonist $\left(r=0.29, R^{2}=8 \%, p=0.634,5\right.$ studies, 5 data points; Fig. 4b) EMG duration (Additional file 2: Table S2).

\section{Discussion}

The present systematic literature review characterized associations between practice-related changes in motor performance and muscle activity in healthy individuals considering different myoelectric variables (i.e., agonist and antagonist EMG amplitude and duration). This research is important for a better understanding of myoelectric adaptation processes initiated by motor practice. Especially, we focused our analyses on well-established EMG measures in the amplitude (e.g., iEMG, RMS) and time (e.g., time to peak muscle activation) domain because these are particularly related to modifications in the spatial and temporal characteristics of muscle force production following practice. We hypothesized that improvements in motor performance following practice are accompanied by reductions in EMG amplitude and duration, especially observed in the agonist muscle. We found only small-sized associations between practicerelated alterations in motor performance and agonist and antagonist muscle activity. This finding was independent from the used data source, that is, associations reported in the literature and correlation coefficients additionally calculated from extracted pre and post practice data for measures of motor performance and myoelectric activity. In general, our findings indicate that practice-related changes in motor performance might only partly be explained by changes in quantitative myoelectric parameters (i.e., agonist and antagonist EMG 


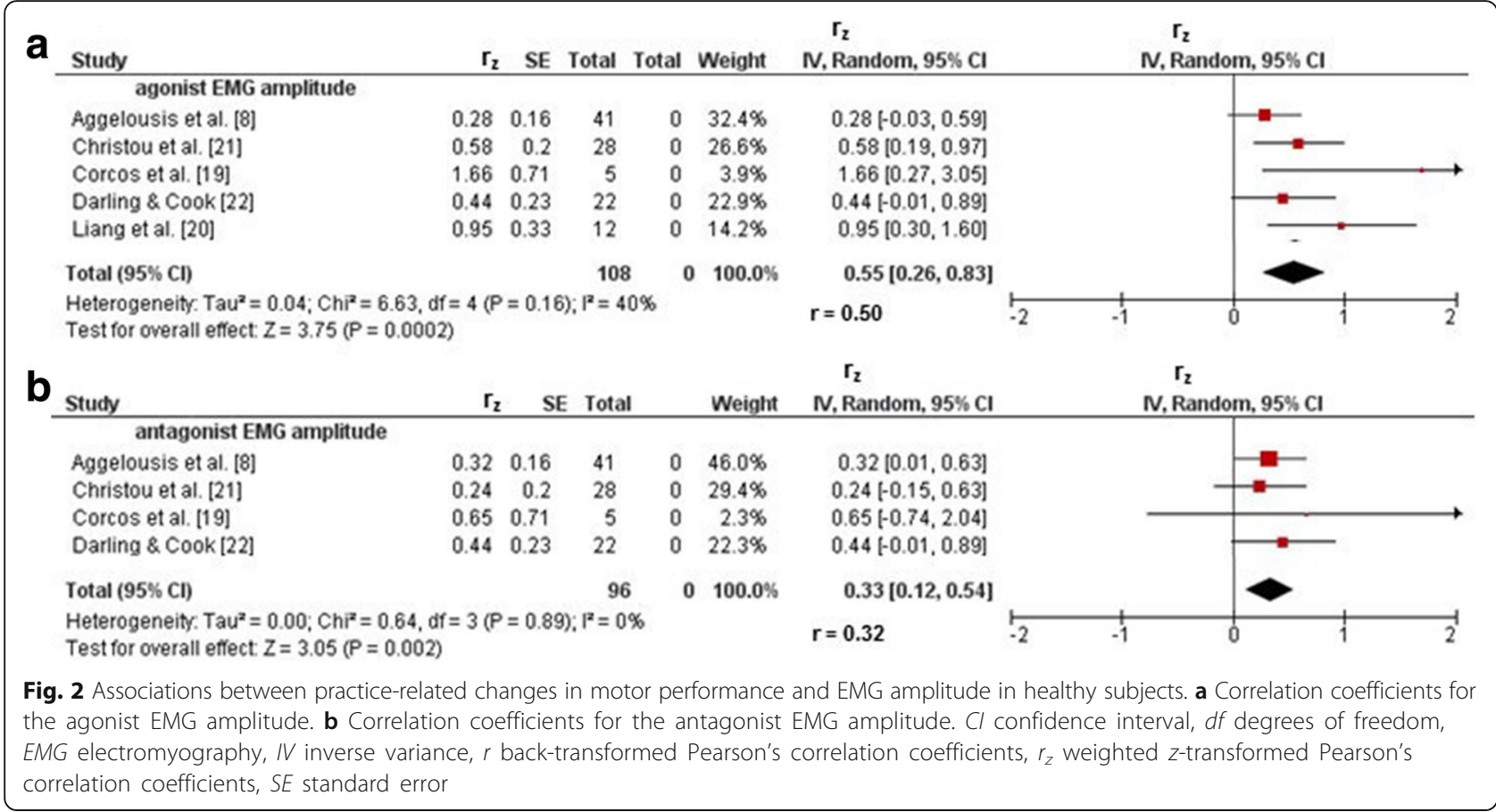

amplitude and duration). A possible reason for the small-sized associations between practice-related alterations in motor performance and agonist and antagonist muscle activity could be the concurrent effect of skill acquisition on qualitative EMG parameters, such as the timing of muscle activity or the amount of coactivation. In this regard, previous research [2-4] showed that during motor practice, the EMG pattern alters from continuous and overlapped muscle activity (i.e., early in practice) to phasic and reciprocal activation (i.e., late in practice). As a consequence, further research is needed to determine the relationship between changes in motor performance and qualitative EMG variables due to motor practice. Additionally, besides the mentioned changes in qualitative myoelectric parameters, adaptations in kinetic (e.g., joint torques, forces) and kinematic (e.g., joint positions, angles, angular velocity, acceleration) variables might have influenced our findings of small-sized correlations between changes in motor performance and muscle activity following practice. For example, Corcos et al. [19] reported significant improvements in movement kinematics (e.g., increased peak moment velocity and acceleration) as a function of practice in young adults aged 20 to 25 years. Further, Christou et al. [21] showed that practicing an endpoint accuracy task resulted in a significantly reduced variability of the force trajectory, peak force, and time-to-peak force in healthy adults and was significantly related (range $r=0.394-0.585$ ) to the improvement in time endpoint error. Thus, we recommend that future studies should add kinetic and kinematic analyses to the investigation of modifications due to motor practice.
The observed correlations differed in terms of their direction. More specifically, in four out of five studies that previously reported correlation coefficients between practice-related changes in motor performance and agonist EMG amplitude, the $r$ value was positive. Contrary, a negative $r$ value was obtained from the extracted pre and post practice data between motor performance and agonist EMG amplitude. However, the reason for this findings cannot unambiguously be explained using our data set because only three of the included 20 data points indicated an increase in myoelectric activity although motor performance improved as a result of practice. Additionally, positive associations were detected for practice-related changes in motor performance with agonist and antagonist EMG duration but negative relationships were found for motor performance with agonist and antagonist EMG amplitude. In other words, as motor performance improved agonist and antagonist EMG duration decreased, yet agonist and antagonist EMG amplitude increased. What are likely explanations for the observed difference in correlation direction? A decrease in agonist and antagonist EMG duration corresponds with reports $[6,16,25]$ of reductions in movement time required to execute a practiced task. With regard to agonist EMG amplitude, an increase could be caused by the specific demands of the utilized practice task. More specifically, when the goal is to increase the speed of limb movement during practice (e.g., to perform fast accurate movements $[19,22])$, this would lead to an increase in the magnitude of muscle activity (e.g., agonist EMG amplitude) as proposed by 


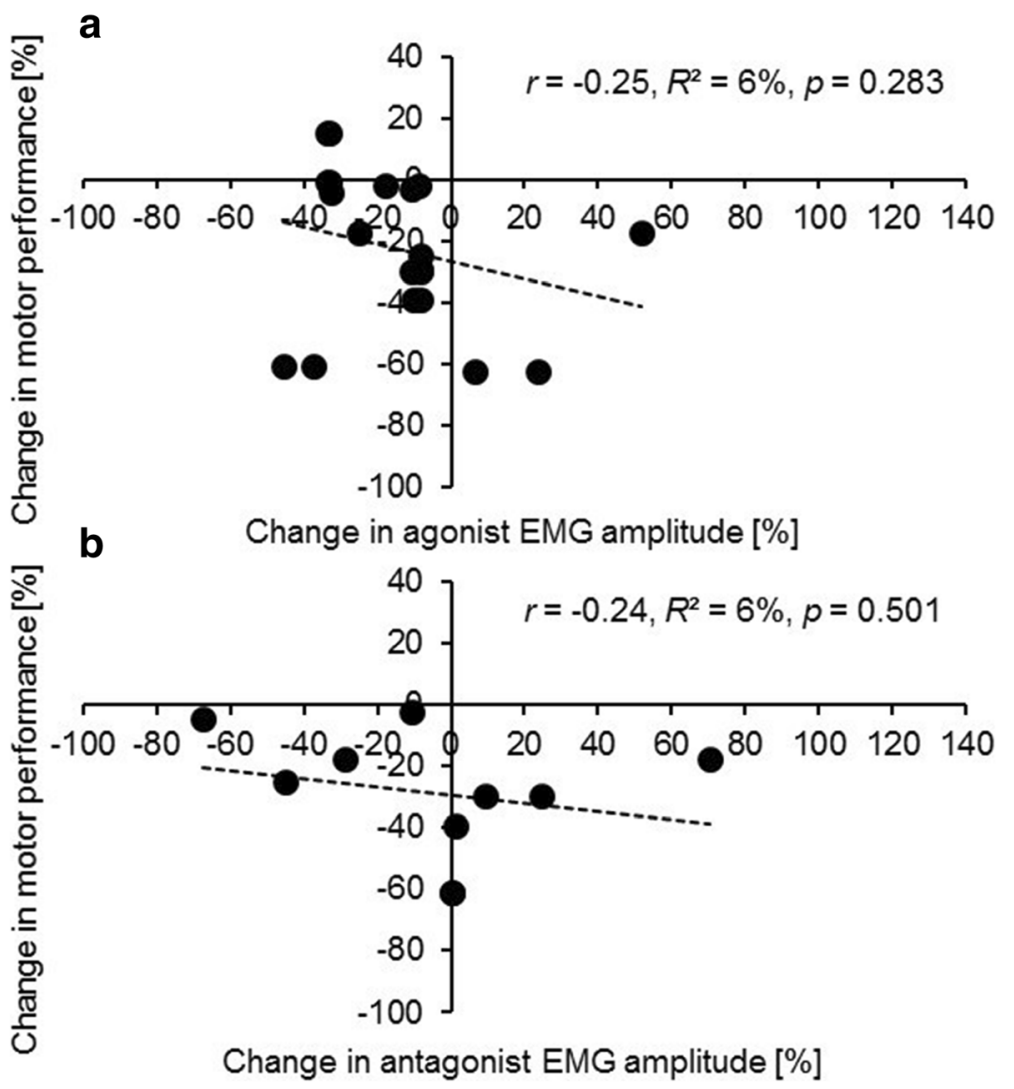

Fig. 3 Associations between practice-related changes in motor performance and EMG amplitude in healthy subjects extracted from 11 studies. a Data points for the agonist EMG amplitude (11 studies, 20 data points). b Data points for the antagonist EMG amplitude (7 studies, 10 data points). The number of data points is larger compared to the number of studies because a few studies studied multiple muscles. Muscles acting as both agonist and antagonist were excluded from data analyses. EMG electromyography, $r$ Pearson's correlation coefficients, $R^{2}$ coefficient of determination

the "speed-sensitive strategy" [28]. In terms of antagonist EMG amplitude, an increment might be elicited by the specific role of antagonist muscles when performing the practice task. Contrary to agonist muscles that are responsible for efficient movement execution, antagonist muscles mainly have assistive or stabilizing function necessary to decelerate the limb movement that leads to extended myoelectric activation [12].

\section{Limitations}

A limitation of this systematic review is that only five studies were found that reported correlation coefficients for alterations in motor performance associated with those in muscle activity. To increase sample size, we additionally extracted pre and post practice data for measures of motor performance and muscle activity from another 17 studies. From this, percent change values were calculated followed by correlational analyses. As a consequence, an indirect comparison of practicerelated changes in motor performance with muscle activity was performed that requires substantiation by further studies that directly compare practice-related alterations in motor performance associated with changes in muscle activity via correlational analysis. Further, practice-related alterations in motor performance were assessed along with associated changes in quantitative (i.e., EMG amplitude, duration) but not in qualitative (i.e., timing of muscle activity, amount of coactivation) myoelectric variables or other biomechanical variables (i.e., kinetics and kinematics). Thus, we recommend that future studies should conduct comprehensive electromyographic examinations together with kinetic and kinematic analyses of pre and post practice data. In addition, the observed practicerelated changes in muscle activity could be influenced by differences in the used practice task (i.e., maximal versus submaximal effort tasks). Maximal effort tasks such as fast/ballistic accurate movements were investigated in six studies and require an increase in limb speed, and thus, an increase in EMG amplitude would be an appropriate change. Submaximal effort tasks were examined in 18 studies and include target- 


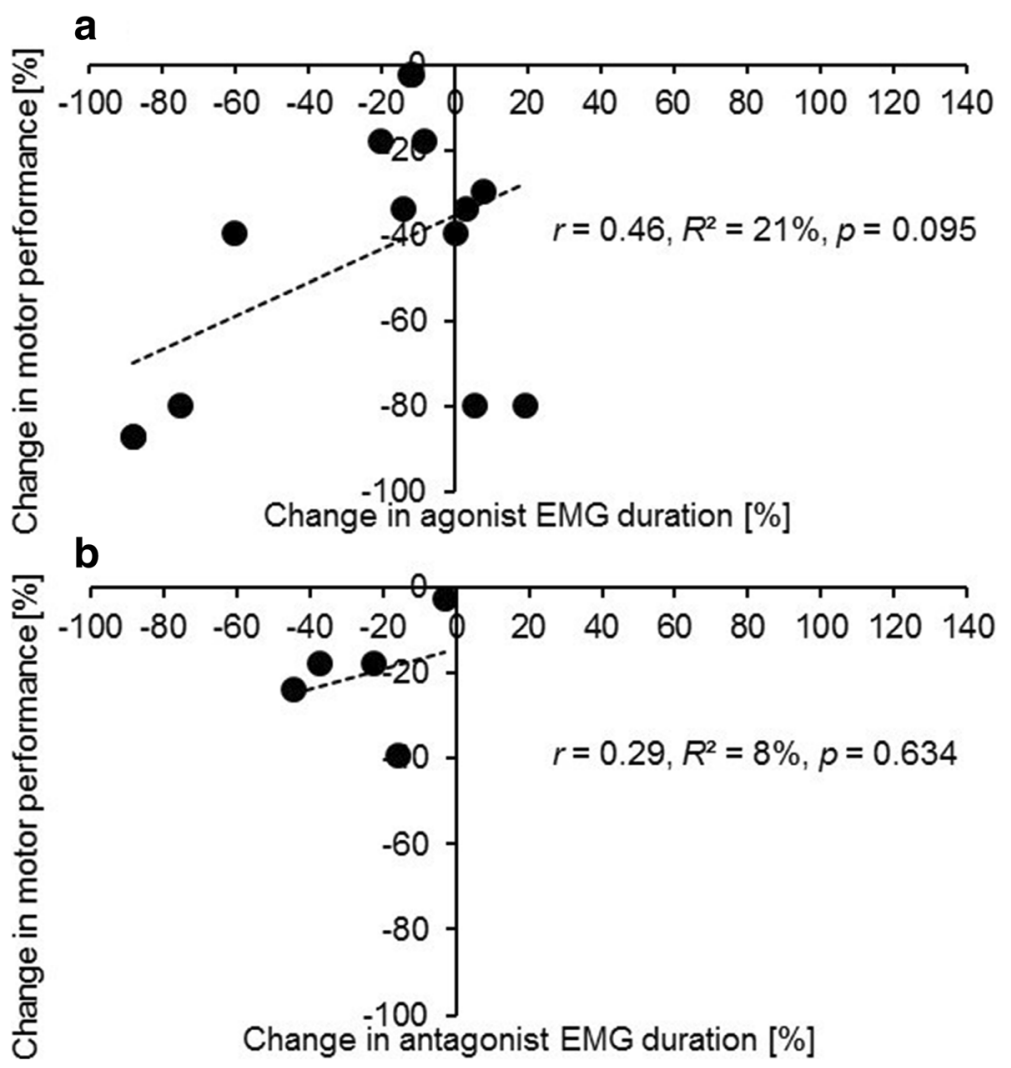

Fig. 4 Associations between practice-related changes in motor performance and EMG duration in healthy subjects extracted from 9 studies. a Data points for the agonist EMG duration (8 studies, 14 data points). b Data points for the antagonist EMG duration ( 5 studies, 5 data points). The number of data points is larger compared to the number of studies because a few studies studied multiple muscles. Muscles acting as both agonist and antagonist were excluded from data analyses. EMG electromyography, $r$ Pearson's correlation coefficients, $R^{2}$ coefficient of determination

oriented and time-/velocity-constrained movements where the goal is to reduce movement error, time, or velocity. In this case, a decrease in EMG amplitude and duration would be an adequate adaptation. As a consequence, further research is needed to determine whether practice task category (i.e., maximal versus submaximal effort task) influences the relationship between practice-related changes in motor performance and muscle activity in healthy individuals. Finally, correlations do not show cause and effect. Hence, the investigated associations could be affected by other not yet examined variables such as alterations in qualitative (i.e., timing of muscle activity, amount of coactivation) myoelectric parameters or other biomechanical variables (i.e., kinetics, kinematics).

\section{Conclusions}

The present systematic review revealed small-sized correlations between practice-related changes in motor performance and agonist and antagonist EMG amplitude and duration in healthy individuals. Our findings indicate that practice-related adaptations in motor performance of healthy persons can only partly be explained by changes in quantitative myoelectric measures. Consequently, future studies investigating practice-induced adaptations are advised to integrate qualitative myoelectric as well as other biomechanical variables (i.e., kinetics, kinematics).

\section{Additional files}

Additional file 1: Table S1. Pre and post practice data for motor performance and EMG amplitude. (XLSX $37 \mathrm{~kb}$ )

Additional file 2: Table S2. Pre and post practice data for motor performance and EMG duration. (XLSX $31 \mathrm{~kb}$ )

Acknowledgements

None.

\section{Funding}

We acknowledge support by the Open Access Publication Fund of the University of Duisburg-Essen.

Availability of Data and Materials

All data and materials are available in this manuscript. 


\section{Authors' Contributions}

The last author (TM) designed the research question and conducted the initial review and first manuscript draft. The first author (DB) conducted the entire literature search using the selection criteria and coding of studies and performed the statistical analyses. The second author (RK) contributed substantially to all sections of the manuscript. All authors read and approved the final manuscript

\section{Ethics Approval and Consent to Participate}

Not applicable.

\section{Consent for Publication}

Not applicable.

\section{Competing Interests}

Dennis Brueckner, Rainer Kiss, and Thomas Muehlbauer declare that they have no competing interests.

\section{Publisher's Note}

Springer Nature remains neutral with regard to jurisdictional claims in published maps and institutional affiliations.

\section{Author details}

'Division of Sports Medicine and Engineering, Hochschule Koblenz-University of Applied Sciences, Remagen, Germany. ${ }^{2}$ Division of Movement and Training Sciences/Biomechanics of Sport, University of Duisburg-Essen, Gladbecker Str. 182, 45141 Essen, Germany. ${ }^{3}$ Department of Health and Social Affairs, FHM Bielefeld-University of Applied Science, Bielefeld, Germany.

Received: 5 October 2017 Accepted: 29 January 2018

Published online: 08 February 2018

\section{References}

1. Schmidt RJ, Wrisberg CA. Motor learning and performance: a situationbased learning approach. Human Kinetics: Champaign; 2008.

2. Person RS. An electromyographic investigation on coordination of the activity of antagonist muscles in man during the development of a motor habit. Pavlovian J of Higher Nervous Act. 1958;8(1):13-23.

3. Kamon E, Gormley J. Muscular activity pattern for skilled performance and during learning of a horizontal bar exercise. Ergonomics. 1968;11(4):345-7.

4. Moore SP, Marteniuk RG. Kinematic and electromyographic changes that occur as a function of learning a time-constrained aiming task. J Mot Behav. 1986:18(4):397-426.

5. Lay BS, Sparrow WA, Hughes KM, et al. Practice effects on coordination and control, metabolic energy expenditure, and muscle activation. Hum Mov Sci. 2002;21(5-6):807-30.

6. Gabriel DA, Boucher JP. Practicing a maximal performance task: a cooperative strategy for muscle activity. Res Q Exerc Sport. 2000;71(3):217-28.

7. Heise GD. EMG changes in agonist muscles during practice of a multijoint throwing skill. J Electromyogr Kinesiol. 1995;5(2):81-94.

8. Aggelousis N, Mavromatis G, Gourgoulis V, et al. Modifications of neuromuscular activity and improvement in performance of a novel motor skill. Percept Mot Skills. 2001;93(1):239-48.

9. Engelhorn R. Effects of skill practice on electromyographic activity patterns and frequency spectra. Hum Mov Sci. 1987;6(2):117-31.

10. Kenny DA. Statistics for the social and behavioral sciences. London: Longman; 1987.

11. Vincent WJ. Statistics in kinesiology. Human Kinetics: Champaign; 1995.

12. Hobart DJ, Kelley DL, Bradley LS. Modifications occurring during acquisition of a novel throwing task. Am J Phys Med. 1975;54(1):1-24.

13. Hobart DJ, Vorro JR, Dotson CO. Synchronized myoelectric and cinematographic analysis of skill acquisition. J Hum Mov Stud. 1978; 19(4):155-66.

14. Payton OD, Su S, Meydrech EF. Abductor digiti quinti shuffleboard: a study in motor learning. Arch Phys Med Rehabil. 1976;57(4):169-74.

15. Dugas C, Marteniuk RG. Strategy and learning effects on perturbed movements: an electromyographic and kinematic study. Behav Brain Res. 1989;35(3):181-93.

16. Gabriel DA. Changes in kinematic and EMG variability while practicing a maximal performance task. J Electromyogr Kinesiol. 2002;12(5):407-12.
17. Klein Breteler MD, Simura KJ, Flanders M. Timing of muscle activation in a hand movement sequence. Cereb Cortex. 2007:17(4):803-15.

18. Hasson CJ, Caldwell GE, van Emmerik RE. Changes in muscle and joint coordination in learning to direct forces. Hum Mov Sci. 2008;27(4):590-609.

19. Corcos DM, Jaric S, Agarwal GC, et al. Principles for learning single-joint movements. I. Enhanced performance by practice. Exp Brain Res. 1993; 94(3):499-513.

20. Liang N, Yamashita T, Ni Z, et al. Temporal modulations of agonist and antagonist muscle activities accompanying improved performance of ballistic movements. Hum Mov Sci. 2008;27(1):12-28.

21. Christou EA, Poston B, Enoka JA, et al. Different neural adjustments improve endpoint accuracy with practice in young and old adults. J Neurophysiol. 2007:97(5):3340-50

22. Darling WG, Cooke WG. Movement related EMGs become more variable during learning of fast accurate movements. J Mot Behav. 1987;19(3):311-31.

23. Normand MC, Lagasse PP, Rouillard CA, et al. Modifications occurring in motor programs during learning of a complex task in man. Brain Res. 1982;241(1):87-93.

24. McGrain P. Myotemporal changes associated with learning a simple motor task using different strategies of movement. J Hum Mov Stud. 1986;12(2):59-70.

25. Gabriel DA, Boucher JP. Practice effects on the timing and magnitude of antagonist activity during ballistic elbow flexion to a target. Res Q Exerc Sport. 1998;69(1):30-7.

26. Morrison S, Anson JG. Natural goal-directed movements and the triphasic EMG. Mot Control. 1999;3(4):346-71.

27. Ludwig DA. EMG changes during acquisition of a motor skill. Am J Phys Med. 1982;61(5):229-43.

28. Corcos DM, Gottlieb GL, Agarwal GC. Organizing principles for single-joint movements. II. A speed-sensitive strategy. J Neurophysiol. 1989;62(2):358-68.

\section{Submit your manuscript to a SpringerOpen ${ }^{\circ}$ journal and benefit from:}

- Convenient online submission

- Rigorous peer review

- Open access: articles freely available online

- High visibility within the field

- Retaining the copyright to your article

Submit your next manuscript at $>$ springeropen.com 